\title{
Amateur Creation and Entrepreneurialism: A Critical Study of Artistic Production in Post-Fordist Structures
}

\author{
Yiannis Mylonas
}

\author{
Media and Communications Department, University of Lund, Lund, Sweden, Yian- \\ nis.Mylonas@kom.lu.se
}

\begin{abstract}
Based on an interview with a hip-hop artist from Eastern Poland, this article critically assesses amateur art production proliferating throughout the globe today through individuals' creative usages of new ICTs and new media affordances. The post-Fordist material and ideological context of contemporary social life is the main focus point of the article's critique. Scarcity, dispossession, and entrepreneurship are the main analytical concepts used to develop a critical analysis and explanation of mainstream realities of amateur artistic production today. Within a context defined by precarious work conditions and prospects, material scarcity, and consumerist aspirations, media and technological potentialities are strategically used by the amateur artist-entrepreneur a) as resources where creativity is put to work for potential socio-economic elevation and inclusion in the global industrial artistic scene (in the case of private ICT), b) as "free" resources, appropriated for entrepreneurial aspirations (in the case of "free" digital material circulating online, particularly through peer to peer networks), c) as channels for self promotion and networking (in the case of web 2.0 structures). What is often less apparent to the amateur artists, though, concerns the exploitative capacities of corporate Internet to dispossess amateur work and online social relations for the purposes of capital accumulation and reproduction. Unless critiqued, "free culture" -generated by new ICTs and new media- is assimilated by the material and ideological power of late capitalism and is "put to work" for the (re)production of late capitalism. The article concludes by suggesting the critical challenging of the mainstream artistic identity and the critical use and appropriation of new media/ ICT's potentialities.
\end{abstract}

Keywords: Entrepreneurialism, Subjectivity, ICT, Internet, Post-Fordism, Neoliberalism, Amateurism, Artists

Acknowledgement: The author wishes to warmly thank Ms Teresa Klimowicz for her crucial help in conducting the particular research.

\section{Introduction: ICT Amateurism and Entrepreneurial Subjectivity}

This article aims at a critical approach of the lived social realities of amateur artists using new ICT and new media to produce, develop and communicate (or rather, to promote) their work, in a competitive, commercial and globalized environment (Bauman 2005, 59), where living conditions are undergoing major, constant changes, and are being exposed to vast contradictions and controversies. The concept of the entrepreneur (Brown 2003; Ong 2006) is central in understanding the subjectivity of the amateur artist and the transformation of the very identity of the artist, in a precarious and stagnated, post-modern social environment proliferated by commodity fetishism, deferred fantasies of opportunity, political exceptionalism and unequal social relations. Entrepreneurship is the neoliberal imperative of "exodus" from a deteriorating condition of enforced scarcity, that focuses on the mobilisation of the individual self for the achievement of social inclusion. Inclusion mainly concerns one's participation in the antagonistic terrain of neoliberal society that can potentially lead towards the acquisition of economic, social and cultural capital. Economic capital in particular is constantly monopolized by particular transnational agents through different processes of exploitation and dispossession, principally through new, digital forms of enclosure (Andrejevic 2002, 245).

I would like to theoretically frame the transformation of artistic work and artistic identity towards entrepreneurial ends, in relation to the following variables: a) the biopolitical nature of post-Fordist labour, where earlier dichotomies between work and leisure, or between the public and the private sphere are blurred $b$ ) the position of new information and communication technologies (ICT) and new media in relation to the transformation of economic production, consumption and communication processes, and the production of a void in regulations that works to the benefit of the most economically and politically powerful social agents; c) the unequal relations of production and the status of ownership of production means by late capitalist agents and the enforced scarcity they sustain, expanding towards immaterial domains; d) the narcissistic, post-political self, and the desires of success sustained by commodity culture and the myth of the talented artist, proliferated by the creative possibilities provided by participatory culture. 


\section{Post-Fordism and Neoliberalism as Central Variants Defining Contempo- rary Social Conditions and "Spirit of Times"}

The purpose of this section is to emphasize the conditions and processes developing entrepreneurial subjectivities. The main explanatory frames drawn are the post-Fordist conditions of biopolitical economic production, and neoliberal ideological incentives and internalized rules of self conduct. An overview of the socio-cultural conditions of post modern societies, as discussed by critical scholarship (Bauman 2000; Baudrillard 1997), is outlined to demonstrate the stagnated context where entrepreneurial subjectivity develops. Neoliberalism and post-Fordism will be shortly presented as interconnected variables of late capitalism (Price 2011, 56), in order to analyze the social conditions of post/late modernity. Developments in new media and information technologies will also be discussed from a critical angle, in order to highlight their position as resources of entrepreneurialism, exploitable by late capitalist accumulation and value production.

\subsection{Post Modern Socio-Cultural Conditions}

Life is hard in post-modern societies for the vast majority of their population, primarily due to the oppression caused by scarce living conditions. Scarcity concerns the lack of material resources necessary for the development of the "good life" and the sustaining of biological life by the majority of humans in the world, and by increasingly larger number of Western populations that up until now enjoyed a higher standard of living than people from other parts of the world. Post modern societies are stagnated, Bauman $(2006,84,86)$ argues, by excess and profligacy, redundancy and prodigal waste.

Stagnation seems to underline the condition of excess and surplus that superficially characterizes post modern, consumerist, late capitalist societies. Excess (Pasquinelli 2008, 55) concerns the process of overproduction of commodities, accompanied by the bi-production of waste that is intrinsic to any productive process. Excess also concerns saturation and fatigue due to the overflow of consumer products, the infinite projection of possibilities of identity and life change, or the recycling of styles and desires related to commodity needs, which are fabricated by consumer society and the cultural industries (Adorno 1991; Baudrillard 1997; Bauman 2007). The contradictory coexistence of scarcity and excess can be viewed in the acceleration of hard working well educated, "talented", flexible individuals, capable of developing different kinds of work projects, forced to compete each other against exclusion, and being equally exploited by post-Fordist labour conditions. Bauman, following Beck, argues, the individual is expected to find "biographic solutions on systemic contradictions" $(2000,38)$. As Bourdieu writes, a Darwinian universe emerges, "of insecurity, suffering and stress" (1998).

\subsection{Post-Fordism}

Post-Fordism is a socio-economic model of commodity production that developed after the crisis in profit and growth encountered by Fordism, a rigid model of production, based on "hard" industry, central planning, production of scale and mass consumption. Post-Fordism responded to the increasing problems of capital accumulation that Fordism encountered. David Harvey (1989, 147) describes post-Fordism as flexible accumulation. Post-Fordism relies on a rationality of flexibility that blends work with free time, requires reflexive management based on market surveys and marketing strategies, outsourcing of production, and production planning that relates to scope other than scale. As Harvey argues "the more flexible motion of capital emphasizes the new, the fleeting, the ephemeral, the fugitive, and the contingent in modern life, rather than the more solid values implanted under Fordism" $(1989,171)$.

The shift to the post-Fordist paradigm of accumulation was capital's response to the ongoing social dissidence escalating in the West during the 1960's and 1970's, partly related to the mass rising of the living standards and to the development of individual autonomy (Boltanski and Chiapello 2006). Capital reacted to the new social demands for creative and flexible work, by reorganizing itself according to the particular social demands. The defeat of social struggles further probed individualist radicalism towards the reactionary alternative offered by capital and disconnected itself from emancipatory social imaginaries.

Reproduction of capital and the sustaining of accumulation, require innovation and expansion. The fluid and fragmented conditions of late modern societies though produce indefinite ruptures and contingencies to political economic objectives. Capitalism addresses such problems by customizing the production process to the fluid and fragmented character of late modern everyday life. Post-Fordism blends work time with leisure in the expense of leisure; leisure time increasingly re- 
lies on consumer habits, which are further "put into work" themselves, in order to keep track of the constant motion that is characteristic to capitalism. Most importantly, Virno $(2009,59)$ notes that post-Fordism reproduces itself through the assimilation of informal, communicative behaviors and creative practices, developed in the lifeworld, what he and others (Pasquinelli 2008) drawing on Marx's notion of the "general intellect" - developed in the Grundrisse - describe as the "common".

The idea of the "project" is characteristic of late capitalist work and production processes. The project is tied to a mode of life organized in "episodes" (Bauman 2005b, 36), where constant motion and development is required for one to avoid exclusion from work and social life in general terms. "Openness" though is underlined by an increasingly utilitarian perspective, where reflexivity is goal-orientated, highly controlled by a strict instrumental gaze in search for entrepreneurial opportunities (Lovink and Rossiter 2007, 14), guised as a process of free, endless exploration. The identity of the entrepreneur (Brown 2003) is central in late capitalist societies. Entrepreneurialism is a strategy of survival in a precarious social terrain.

\subsection{Neoliberal Subjectivities}

This section raises a question of control in the previous discussion. How is the individual, with its increased late modern autonomy, diverted to exploitative ends? The partial answer to this question lies in the structural, material order of post-Fordism and the consequences of the capitalist economic and social inequalities. A deeper problem though is an ideological one: how do such inequalities - other than exploitative and exclusive - come to be viewed, not only as natural, but as opportunities as well? How is "voluntary submission" (Stavrakakis 2007, 263) to late capitalism produced, without provoking massive forms of resistance? Answers to such questions can be addressed by considering ideological and institutional issues along with material ones (Wayne 2003, 177 ), relating to the governing modes and principles of post-Fordist social conditions.

As an ideology -though relevant to conservativism, in terms of the general economic aspirations or the ontological premises of rationality and individual responsibility - the neoliberal resentment of stability marks sharp differences from the paternalistic and traditionalist aspirations of conservatives (Harvey 2005). Neo-liberalism cultivates social differences, other than attempting social cohesion. The positive understanding of freedom in neoliberal thought as pro-active is understood within an individualist, utilitarian framework. This way, political and social concerns of emancipation are downplayed by forms of personal empowerment and subjective freedom. Without socio-political understandings of restrictions of freedom, the neoliberal socio-political system is confirmed and normalized (Rose 1999, 233), with people striving on an individual level to fulfill the tasks that will assert their freedom.

Drawing on liberal notions of "free" market economy, private property, entrepreneurialism, neoliberalism attempts a post-political affirmation of social order. Ong $(2006,6)$ argues that neoliberalism is a form of "new political optimization". As a global hegemonic project, neoliberalism establishes itself through an exception. This exception is the neoliberal post political reification. Like any form of social construction, a non-political assertion of society produces specific collective mentalities, specific identities, new forms of knowledge, and specific social relations. Neoliberalism is not only about institutions producing rules and policies, but is a form of social organization and a set of rules to guide individual living.

Biopolitics concerns the politicization of all aspects of life, and their subjection to the regulation of the sovereign power. The post-Fordist mode of production relies on the operationalization of the "general intellect", informal aspects of everyday and private life, communication, creativity or language. The development of an individual consciousness that acknowledges the informal potentials of humans as strategic resources of growth, concerns the development of a neoliberal subjectivity, related to the self-actualization of the individual towards the development of skills, techniques and entrepreneurial initiatives.

Neoliberal control is accomplished through formation other than repression. To govern, Rose $(1999,4)$ writes, is to act upon action to understand the domains and entities to be governed, and to instrumentalize their forces in order to shape processes towards preferred ends. "Neoliberalism is the art of governing upon the self-activating capacities of free human beings, citizens, subjects" (Ong 2006, 13). Neoliberal governmentality is "the infiltration of market driven truths and calculations in the domain of politics" (Ong 2006, 4). Governmentality works as the mechanism of selfcontrol, but also elaborates on particular tasks necessary for the individual to produce him/herself as free, flexible or autonomous (Lemke 2001, 203).

The neoliberal subject relates to the classical economic idea of homo-economicus, but also transgresses its liberal limits (Lemke 2001, 200). The neoliberal subject is a mixture of homo economicus and homo ludens, the playful individual that is flexible to adjust to new social- 
environmental demands and to endlessly explore different possibilities. A new form of economic citizenship develops (Rose 1999, 244) producing new form of morality that gives meaning to individual life. Identity is to be found in work, and should also relate to concerns of the workplace for success, efficiency, productivity. Consumerism and lifestyle maximization further affirm the gratifications of the performance of the individual, in line to corporate aspirations of social life.

The neoliberal subject is instrumentalist, efficient, cost-benefit calculative, purpose-driven, utilitarian and above all competitive; he/she is responsible for his actions and state of being. The neoliberal citizen (Brown 2003; Lemke 2001) responds to the values and the beliefs of a society orientated towards private economic ends. The model-citizen, the entrepreneur, seeks the maximization of his-her profit and pursues his/her goals. "The market system becomes a value in itself" (Harvey 2005, 3).

\subsection{New Media, New ICT, Entrepreneurialism and Exploitation}

New media and new ICT have been catalytic to profound late modern social and economic changes. For instance, post-Fordist reflexivity would be impossible without ICT infrastructures. Different scholars (Jenkins 2006; Gauntlett 2011) share optimist ideas on the potential entailed in new media and new ICT for the advance of human autonomy and the deepening of democracy. One needs to be skeptical towards the optimism that idealizes the freedom developed through new media structures and affordable ICTs technologies. Democratic, empowering and emancipatory potentials do exist in creative, individual and participatory uses of new ICTs and new media, but such potentials are not defacto immanent. They rely on counter-hegemonic discursive frameworks and material circumstances. Virno $(2004,40)$ stresses the prevalence of the "negative possibilities" in the potentials entailed in the practices developed by multitudes of individuals today, as capitalism effectively spins them towards accumulative ends. In that sense, "the (post-Fordist) crisis of labor" due to the wealth produced by the commons, the lifeworld and the general intellect, "is reflected in the multitude itself" (Virno 2004, 101).

Critical studies of mainstream new media (Andrejevic 2002; Jakobsson and Stiernstedt 2010) demonstrate that the Web 2.0 user has no control over the usage of his/her material by third parties to generate economic value. Profit from users' unpaid work is generated primarily through advertising (Fuchs 2011, 154) that targets specific profiles of users, created by the reflexive monitoring of their activity online. The economic value of advertising space in media further rises according to a given media's popularity and use. Popularity of a given mainstream web 2.0 platform relies on the free work of users who regularly upload and communicate their thoughts, interests and creative material online.

For Andrejevic $(2002,236)$, the act of watching in online environments, is also a case of surveillance, through the monitoring of users activities, rating possibilities available for users to evaluate the online content. Surveillance of web 2.0 users' activities rationalizes the process of immaterial labour. As Lazzarato argues in his thesis on immaterial labour, "the process of the production of communication becomes immediately the process of valorization" $(1997,9)$. In the same terms, Terranova (2000: 50) argues that the consumption of bandwidth and the passionate involvement with online activities is central to the production of economic value in web 2.0 environments.

In line to Harvey (2010), Jakobsson and Stiernstedt (2010) argue that web 2.0 immaterial labour is a form of Web 2.0 dispossession of users' means of production in the informational realm, which is a crucial domain of late capitalist production of value, reproduction of capitalist production process and capitalist accumulation. What is being dispossessed in web 2.0 is users' creativity, imagination, communication and autonomy (pp 10). The post-Fordist diffusion of labour and leisure reconfigures a "destructive dialectic" (Fuchs 2011, 157, 158) of labour and play, because fun and joy are subsumed by capital and exploited by the later. Play is commoditized and further becomes labour and toil, generating surplus value for Internet companies, due to the aforementioned, late modern material scarcity (Fuchs 2011, 159). A form of biopolitical model of capital reproduction rises, where users' attention, imagination, time, identity and socialization is succumbed in reflexively controlled digital environments, sustained by "fun", individualistic aspirations, and the deferred possibility of succeeding in the acquisition of cultural, social and economic capital, through the uncritical identification with the myth of the artist.

\section{Post-Fordist Lifeworlds}

Within the aforementioned context, arts and culture, along with their potentials as critical spaces for socio-political intervention, are under considerable pressure. An entrepreneurial attitude in creating and in communicating artistic work is noted by different critical scholars (Lovink and Rositer 
2007, 14; Ross 2007, 22). Arts and the identity of artists is developing in line to broader social changes that reshape cities, work and the lifeworld, the space of human activity that was once (Habermas 1989) considered outside the reach of social systems' control-nowadays a vital part of late capitalist mode of value production, consumption and reproduction of capital.

The rise of an entrepreneurial subjectivity will be reflexively approached in the empirical realities of art today, "amateuristically" developed by multitudes of individuals working with new media and ICTs, in transnational, post-Fordist social terrains. Hesmondhalgh $(2007,68)$ noted that the dystopian claims of "immaterial labor" critics are often not grounded in empirical research. The "artist in the age of social reproduction" (Paquinelli 2008, 49) struggles in a highly competitive "glocal" terrain to make a difference by putting his/her life to work. As Lovink and Spehr $(2007,86)$ note, the contemporary fluid terrain of creative production is a highly competitive and exploitative environment, despite the freedom allowed by media affordances to produce and to distribute one's work. The amateur-artist's efforts to "break out" from the challenges posed by intense global antagonism and material scarcities are approached through literature unfolding the "negative" trajectories of the multitudes (Virno 2004; Pasquinelli 2008).

A hip-hop artist was interviewed among other people -young new media and new ICTs users in Lublin, a Polish city located in east Poland, in June 2011. The particular interview was part of a broader, comparative critical research on peer to peer practices, "free culture" and politics in different European countries. The particular artist is male, 27 years old, with a higher education background. His personal information will remain concealed. I am grateful to the artist for agreeing to talk with me on issues related to his artistic work.

The local element of the case serves to emphasize the globality of dominant practices and hegemonic discourses related to creativity, culture, new media usage, identity and work, and disclose contextual particularities, related to historical, political, cultural or economic variables of local specificities. Poland and in particular, its poorest side, the East, is an interesting case to be studied, in order to discuss the realities of late capitalism there, particularly in relation to its own local historical-cultural and political trajectories - mainly concerning Poland's own "communist" legacy - in terms of civic culture and politics.

"Independent" arts and culture in Poland were highly political during the "socialist" era of Poland, opposing the particular regime. The post socialist times saw an increasing focus on the free development of artistic content as well as the development of a do-it-yourself (DIY) scene of artistic production. Independent art remained socially engaged, but was mostly concerned to issues relating to contemporary Polish identity, challenging traditional aspects of Polish society like religion and family values, a case that is not unique to Poland but to post 1990's artistic critique (Boltanski and Chiapello 2006, 425), focusing on identity and cultural issues and avoiding to address capitalism as a central factor of material discontent. Within this social and subcultural context, an artist is approached in line to the earlier theoretical concerns on global dominant tendencies and trends to arts, work, creation and everyday life. Citations that follow are as precise to the actual enunciation and colloquial style of the respondent.

\subsection{Where Spheres Blend: Work and Art, Fun, Experience}

"-Do you download music from the Internet?

-Yes.

-How do you use that material?

-I download, then I listen to the material I downloaded, then I look around for more stuff... you get the stuff inside you and you shoot it out, you get things from friends, (the respondent mentions different names of bands) and then you mix it all up and you add your own feeling to it.

-Are there any music preferences?

Any kind of music; you got to look at everything... you look at all of them and you get what you desire.

-Do you have a record contract?

-Right now, we work on our own, me and a friend of mine. He does the music, I make the creative part. He's got the musical technology knowledge, you got the musical knowledge, and maybe you also got a kind of historical (knowledge). We do it all together; he's like 'change the drums and do it backwards', it's a f-ing collective project and that works best because you don't let your ego eat you up.

- Is it DIY project then?

-Right now we do it on our own. We don't need a company to promote ourselves right now. We do it on our own. We use Facebook. Twitter, Chimber-Myspace sucks because its old-and then, 
who do you trust? Who puts music in Myspace? You link your account in Facebook, it is the main shit right now, and then you plug the leading uploaders and you have it everything together."

The artist works collaboratively and reflexively, by utilizing ICTs to produce his own music with fellow artists across the world; he also uses new media to promote his work, and to construct networks to develop his work and to communicate it to the widest possible audiences. The artist also uses free culture developed in web 2.0 to cover his cultural needs, to provide himself with influences, information, as well as with materials to use for his own work, freely. The creative potential actualized in the fluid, post-modern, translocal and mediatized world - is therefore portrayed in the respondent's description of his work mode. Furthermore, a given music genre (hip-hop) is translated and advanced in Poland, mainly through new media and ICT affordances, transcending the limitations and exclusions of the music market. The availability of music across the Internet develops the local scene of hip-hop, enabling creative advances and interchanges. Thus, a mixing of arts is further accomplished in a "bricollage" way. Autonomy is materialized in the absence of former patronizing and dependence to music companies. The potentials of freedom, participation and creativity of new ICTs that are noted by media scholars (Jenkins 2006; Gauntlett 2011) are apparent: a critical multitude of dispersed individuals develops due to transnational networking, amateurism, and the effects of free culture.

Yet, broader issues related to ideology and structure - important variants that produce the context where social practices develop - disclose the regressive, depoliticized side of the multitude (Pasquinelli 2008, 33). It is questionable then whether creativity and agency unleashed through individualistic late modern social developments and interactive media/technologies, contribute to progressive social change envisaged by new media scholars. Such developments frequently seem to intensify dominant structures and discourses of power, as will be demonstrated in the artist's responses in the following sections of analysis.

The corporate, late capitalist structure of Web 2.0 providing platforms for "free" use, exploits user generated content (UGC) (in our case, the artist's material, which he uploads online to promote himself). The broader conditions of social scarcity oblige (through force or deceit) the artist to disregard the content of rules (even in their exceptional state) that guide web 2.0 structures. Jakobsson and Stiernstedt argue that "the shifting environment of Web 2.0 is in a state of exception, a temporary suspension of the rule of law in order to bring forward the rule of the new" $(2010,6)$. Although the artist is technically the "owner" of his work, his work reproduces corporate web 2.0 platforms (which depend solely on UGC) and generates profit for the companies owning them, through the renewing of web 2.0 content, through the generation of fans that follow the artist online, and through the publicity that the artist attracts for his work that is laid in the aforementioned web 2.0 platforms, which is further translated into the rise of advertising costs. The artist accepts the "struggle" required for the materialization of his goals. The goal and the fantasy of its rewards legitimize all kinds of exceptional conditions that the artist has to face, during an indefinite "meantime" (between where he is and where he should arrive at). The myth of the artist, and its position in the development of an ascetic and simultaneously entrepreneurial subjectivity, will be further discussed in a following section of analysis.

"-Do you share your music?

-For feedback yes. But it always has to depend on me. If I make music I can let someone else use it, rap on it spit on it, give his thought on it. You can get a lyrical artist to spit his own thoughts on your work, they do their own thing we do our own thing.

So, if it works for me I will upload the first track. But if they want more, they have to pay for it, you pay, they pay, you demand people to pay and if you are in this sort of business you got to go for it.

-Do you make a living out of it?

-l'd love to make a living out of music but I also love to translate and I love working at the bar... I don't want to do one thing I want to mix things, I want to fucking do this, this, this and that, I want to remix, rap, translate, rap, and to make cash of rap and make it all together and do it!"

Precarious work conditions, toil and complex labour - the very condition of post-Fordism, flexibility - are narrated by the respondent enthusiastically, as a set of tasks taken voluntary and performed as "hobbies" or beneficial "experiences", despite the uncertainty they entail (Bauman 2005b, 36). The artist seems to enjoy overworking in different positions -non artistic ones as welland being fluid in more general terms, thus voluntarily succumbing to the material precarious conditions imposed by late capitalism. Precarity is articulated as choice and lifestyle, other than an ex- 
pression of economic relations (Von Osten 2007, 58). The issue of exploitation, along with considerations on issues such as politics and work are absent in the respondent's discourse contextualizing the broader social condition he is dealing with. Von Osten argues that the hegemonic figure of the creator today, combining work and leisure with innovation, "fully realizes neoliberal ideology with an aesthetic dimension" $(2007,55)$. Bauman $(2007,32)$ argues that consumption rules the ethics of post modern labour, where work is sensationally seen as experience, if not a privilege.

There seems to be a struggle to accumulate symbolic capital in order to develop and to foreground the artistic "uniqueness" and special value, in a highly competitive world (Harvey 2002, 95). New media then are used as free promoters, to develop the respondent's project. It is very likely that autonomy does not challenge the capitalist mentality of the cultural industry. The artist oscillates between his fan identity and his artistic identity, which as we will further see, is maintained through worries and fantasies of "success".

A precarious work condition and a lack of monetary resources, work organically as a control mechanism prohibiting a free return of cultural products online. The artist would require a fee for his music, which is legitimate for an artist to be able to support himself/herself and his/her projects. David (2010) has demonstrated several examples of artists using new media to develop a mode of production and distribution of their work outside the one provided by the music industry. Under certain conditions, the respondent seems to be open to such a direction.

The respondent though does not denounce the music industry, but seems willing to be contracted by a record company. DIY production then seems to be a realistic option for one to begin his/her career, with the possibility of future recognition through the mainstream corporate ways. The industry exploits the free labour of artists by saving money and other resources for artistic promotion, which is carried by the artist him/herself. New media function as self-managed promoters, where the most "successful" artists that will manage to become known in highly competitive, online virtual art stages, will be carried by a company. Exploitation though does not end in a record contract, as very few artists manage to make a prosperous living out of their work; as David (2010) shows, most musicians end up owing money to the record company that signed them.

\subsection{Contextual Aspirations}

"What is the purpose of your project in Poland?

-They are only feeding them here with what they need to survive. In order to be here, what I need to do is that I need to incorporate what they have in LA to what they have here, to transfer it and tell them what they are into... I know a lot -they don't- but they have to f-ing learn, I can teach them ... this country has the potential but they don't have the will to do it. This country has the potential but they don't have the will to do it. $75 \%$ of people here are dressed like bums here, they are dressed with sandals and socks..."

The artistic aspirations of the interviewee are not solely egoistic. A vague imaginary towards the uplifting of a cultural delimitation - that he diagnoses as the reality of contemporary provincial Poland - is evident in the excerpt above. Habermas (1992) emphasized the importance of art (literature in particular for Habermas' account) to the construction of a critical consciousness on public affairs, that was differentiated from economic issues and practices and related to the distinct private sphere of life (the lifeworld). Harvey $(2002,93)$ also stresses the progressive and critical political potential of arts and culture. Simultaneously though, Harvey (as well as Pasquinelli 2008, 20) emphasizes the assimilation of cultural production by the increasingly developing cultural industries, and the commoditization of the artistic product. Arts in such a context become commodities, deprived of critical democratic or emancipatory content.

"Independent" art, as the case of the interviewee's work, preserves the traces of discontent towards commercial culture and retains aspirations of social change. Lovink and Spehr though write that particularly in the case of hip-hop, the scene is "completely sucked up by neoliberalism" (2007, 87). In an effort to "make money" and to produce social capital, hip-hop largely abandoned class and identity issues connected to the early development of the genre. The blending of boundaries between the commercial and the non-commercial, between work and non-work, between leisure, amateurism and professionalism, makes normative distinctions complex and controversial. The interviewee's account does not criticize the commercial-entertaining aspect of cultural production and consumption. Ascent may thus concern superficial ideas of "modernizing" his country, relating to consumption patterns and simulations of Western "cosmopolitan" models, by uncritically accepting the cultural imperialism of Western cultural industries, and by idealizing and exoticizing a vague notion of the "West" as an utopia of individualist freedom and "opportunity", and without criticizing 
global material inequalities relating to the ideological hegemony and political-economical dominance of the "West" to the world.

"I don't know what Poland is now, I f-ing live in the World Wide Web, the only f-ing thing. If it wasn't for the World Wide Web l'd be gone out of here in 1999... I went to Germany, I went to the US and came back but I have my people here and I love them, I don't want to leave my people, I love them, I want to make my album here. But it is not easy. Also, Lublin lost it (becoming European capital 2016) for Wroclaw; but what is Wroclaw really?"

The reference to the missed opportunity of Lublin being Europe's cultural capital 2016, signifies the myth of the creative city (Ross 2007, 30) as a terrain to foster conditions for local creators to advance their position in antagonistic global cultural markets (Harvey 2002, 101; 1989b, 15). The transformation of the earlier industrial character of cities to cultural and knowledge economies, aims at "restructuring a city's identity and social fabric towards a new form of economic production, and to surpass growing social problems relating to unemployment, caused by de-industrialization and outsourcing of production to countries with cheap labour force" (Harvey 1989b, 5). The "cultural capital" status functions as an umbrella "brand", to promote the local artists or "creators", and to give them a "stage" to the rest of Europe and to the (Western) world.

Escapist projections, strong fantasies of recognition and the deferring of particular goals towards the future seem to provide the artist with a reason to struggle and to cope with difficulties, which uptake a further adventurous spin. As Lasch (1979) noted, deference is a limitless sociopsychological condition, related to the disintegration of public life and politics by individualist concerns. A vague reference towards institutional power ("they") probes towards structural issues, but responsibility for cultural or class discontent is cast back to the "people". Class issues are "filtered through personality" (Sennett 1974, 330). As Sennett $(1974,332,333)$ continues, though active in pursuing its goals, the individual absorbed by personal affairs, is passive towards challenging institutionalized rules, which are taken as "given".

A strong ego is an evident driver of the respondent's ambitions, relating to the myth of the talented, charismatic, artistic individual, and departing from the romantic notion of the artist identity (Sennett 2008, 97). Though challenged by the experience of collaboration, the charismatic, narcissistic persona pertains throughout the interview. The developing of amateurism and the accomplishing of social and cultural capital through personal work enhances individual fidelity to the artistic cause of success, recognition and material reward. Simultaneously, the acquisition of cultural capital works in elitist ways, as a scale to compare and to distant himself from the majority of "the Polish people“.

\subsection{Multiculturalism Under Condition}

"-How does Poland relate to a music scene developed in the US? What about racial communities and issues related to racism that concern the development of hip-hop? Do you have such phenomena here (in Poland)?

- A friend shot a video here, for some Coke equivalent we have here... he got beaten up here, he is African American, a friend of mine, and to that I say no, and I say, let the f-ing ignorant burn and swallow, I don't even want to talk about it, they beat up my mate, I hate that."

Identity issues relating to global hip-hop subcultures are also a matter concerning resistance towards regressive sides of the artist's own local and cultural background. The aspect of "artistic critique" that Boltanski and Chiapello $(2006,419)$ refer to while addressing the forms of existing critique in late capitalist societies, is evident as the artist is critical towards racism, xenophobia and intercultural ignorance he witnesses in Poland. Though very important, cultural critique does not refer to the structural and material aspects relating to equality issues.

Simultaneously, anti-racist solidarity is shown to a person working in the cultural industries, going to Poland to provide his expertise in producing a commercial advertisement. Support is conditionally given to someone (post) modern enough. Tolerance of ethnic and sexual diversity is an important aspect of the identity of the creative class (Ross 2007, 28). Multicultural identification though is marked by its difference to a manifest negative form of identity. Polish people often appear as a general category in the respondent's words. A patronizing attitude - reflecting possible 
wounds - along with the use of stereotypes and demeaning jokes, mark the artist's manifest differentiation from that which possibly fails to appear "modern"1 enough.

\subsection{Aspects Concerning Passion}

"-Are you putting money in the making of your album?

-Of course I am! Let me put it this way: did you ever have a girl before? What would have happened if you didn't put something inside? That's how it is with everything. You have to put money on the table. I want to bring it (the artistic project) here and I want to try and see if it works, I don't know if it will. I will record it and I will try to move it around. I want to take my chances and I don't want to loose time here, I want to be heard and to be known."

The reference to this ending remark of the interview is to foreground the aspect of passion, through the respondent's "mechanistic" sexual metaphor, that implies penetration in exchange of production and (possible) success. The libidinal impulse is rooted in the drives of the respondent's ambitions (Pasquinelli 2008, 46). Pasquinelli and also Mumford (2011/1964) argue that the "animal spirit" is an irreducible element of the human condition. Drawing on Marcuse, Fuchs $(2011,158)$ argues that late capitalism represses the drive of pleasure and subsumes its realization within the process of production. Since play and labour are virtually indistinguishable, pleasure is put into work, repressed and distorted through aggressive expressions.

The respondent's accounts were based in experience and instincts, and hardly in principles. Animal instincts resist "logical" odds: despite the "pessimism of the senses, there is optimism in the nerves" (Pasquinelli 2008, 32). Passion is mobilized in multitudes of people through the potentials that are unleashed by information, technologies, experiences, knowledge and broader empowering processes, relating to individualism, technology, media, and post modernity, where the limits of the human condition are constantly being probed and challenged. The ideological and structural context organizes the perspective and the direction of the complex dialectic between reason and passion entailed in humans, unless critiqued and challenged. One needs to rethink politics and change in relation to the "bestial" element, as well as to view the evils and the potentials that the bestial aspect of human life is capable to perform, given the particular context that humans operate. A great deal of contingency always lies in social life that control can never fully capture. As Virno (2004) and post-operaismo scholars argue, the multitudes of social individuals are agents and initiators of elements that systems attempt to capture.

\section{Conclusions}

Deleuze (1990) argues that control society is one of constant modulation, with one being a permanent amateur, always in a process of training, adjustment, self-promotion and improvement (also: Rose 1999, 234). Contingency though is ontological to the human and the social condition. Possibilities for change are always plausible. Such possibilities though, like "selling" one's art without corporate intermediaries, need to be further developed materially and ideologically, in order to provide an antagonistic paradigm that will be attractive to people and will provide some economic, cultural and social revenue to artists. Free culture -besides obvious benefits of higher accessibility and inclusivity from marketed culture - bears different spins: amateurism and entrepreneurism are two important critical aspects that denote the reliance of free culture developed by new ICTs to material and ideological structures, dominant in post-modern society. In such a context, producers have to rely on precarious work external to their art or craft, and remain in what Lovink $(2007,86)$ describes as the "amateurization trap".

Free culture, communication and information can publicly address different alternative practices and counter-hegemonic discourses for one to engage with and escape the systemic pressures imposed by Sisyphean tasks on the individual. Organized networks, that may function as new institutional forms (Lovink and Spehr 2007, 85) could be a move towards an antagonistic direction to capitalism. The collectivities and connections produced through ICT networks may precede further, by engaging to theoretical approaches for a democratic appropriation of technology and media, other than a capitalist one.

As Foucault (2002) has stressed, control mostly occurs subtly through the uncritical affirmation of hegemonic discourses and practices. The neoliberal ideology relates to a system of values, incentives and practices that individuals are invited to elaborate upon. Ideas of property, art produc-

\footnotetext{
${ }^{1}$ The term 'modern' here is used to define something 'up to date', 'trendy' etc, other than as a historical-sociological category.
} 
tion and culture, as well as novelty and talent are relevant in discussions of governmentality and technological innovation and autonomy, related to peer to peer (p2p) ICTs and open-source structures. The lack of a counter-hegemonic political discourse and social imaginary for the future appropriates in established structures, the material and idealist outcomes of freedom in different innovating practices.

A central problem in imagining and organizing resistances to capitalist structures and ideology is the capitalization of the commons in a broad sense, including communication, creativity and broader qualities of human life, for the sake of cultural, social, economic growth. An exit route from such a paradigm relates to a critical awareness of the socio-political and economic context where everyday life and its freedom today are grounded and to the progressive establishment of a sense of self-control over one's acts. Control in that sense means a non-instrumentalist, non-career orientated, critical approach towards arts, creativity and culture. What is also important is the challenging of the romantic notions of the gifted, talented artist, which are easily exploitable by the culture industry and quite likely to get caught in the entrepreneurial matrix of discourses and practices that one should deploy in order to develop one's work. The breaking of such essentialist ideas can relate to a critique to one's own social conditions, of work and living, which can connect to the developing of a new, enriched perspective on what kind of society and world would one like to live in (Mumford 2011/1964) that can be beneficial to the individual and to society at large.

\section{References}

Adorno, Theodor W. 1991. The Culture Industry: Selected Essays on Culture. London: Routledge.

Andrejevic, Mark. 2002. The Work of Being Watched: Interactive Media and the Exploitation of Self-Disclosure. Critical

Studies in Media Communication. 19 (2): 230-248.

Bauman, Zygmunt. 2000. Liquid Modernity. Oxford: Polity.

Bauman, Zygmunt. 2005a. Liquid Life. London: Polity.

Bauman, Zygmunt. 2005b. Work, Consumerism and the New Poor. Maidenhead: Open University Press.

Bauman, Zygmunt. 2007. Consuming Life. Maidenhead: Open University Press.

Baudrillard, Jean. 2005/1970. Consumer Society. Thessaloniki: Nissides. (In Greek).

Boltanski, Luc, and Ėve Chiapello. 2006. The New Spirit of Capitalism. London: Verso.

Bourdieu, Pierre. 1998. Utopia of Endless Exploitation: The Essence of Neoliberalism. Le Monde Diplomatique, December 8.

Brown, Wendy. 2003. Neo-Liberalism and the End of Liberal Democracy. Theory and Event 7 (1): 1-43. Accessed December 10, 2010. http://muse.jhu.edu/login?uri=/journals/theory and event/v007/7.1 brown.html

David, Matthiew. 2010. Peer to Peer and the Music Industry, the Criminalization of Sharing. London: SAGE Publications.

Dean, Judy. 2009. Politics Without Politics. Parallax 15 (3): 20-36. Accessed March 20, 2011. http://hws.academia.edu/JodiDean/Papers/871429/Politics without politics

Deleuze, Giles. 1990. Postscript on the Societies of Control. Pouparlets: Columbia University Press.

Foucault, Michel. 2002. Society Must Be Defended. Athens: Psychoyios. (In Greek).

Fuchs, Christian. 2011. An Alternative View of Privacy on Facebook. Information 2: 140-165. Accessed November 11, 2011. www.mdpi.com/journal/information

Habermas, Jürgen. 1992. Structural Transformation of the Public Sphere. Athens: Nisos. (In Greek).

Hardt, Michael, and Antonio Negri. 2004. Multitude, War and Democracy in the Age of the Empire. London: Penguin.

Harvey, David. 1989a. The Condition of Postmodernity: An Enquiry Into the Origins of Cultural Change. London: Blackwell.

Harvey, David. 1989b. From Managerialism to Enerpreneurialism: The Transformation in Urban Governance in Late Capitalism. Geografisk annaler. Series B, Human Geography 71 (1): 2-17. Accessed September 9, 2011

http://links.jstor.org/sici?sici=04353684\%281989\%2971\%3A1\%3C3\%3AFMTETT\%3E2.0.CO\%3B2-6

Harvey, David. 2002. The Art of Rent: Globalization, Monopoly and Cultural Production. Socialist Register 2002: 93-110. Accessed September 10, 2011. http://www.socialistregister.com/index.php/srv/article/view/5778

Harvey, David. 2005. A Brief History of Neoliberalism. Oxford: Oxford University Press.

Harvey, David. 2010. The Enigma of Capital and the Crises of Capitalism. London: Profile Books.

Hesmondhalgh, David. 2007. Creative Labour as a Basis for a Critique of Creative Industries Policy. In MyCreativity Reader: A Critique of Creative Industries, edited by Geert Lovink and Ned Rossiter, 59-68. Amsterdam: Institute of Network Cultures.

Jakobsson, Peter, and Fredrik Stiernstedt. 2010. Pirates of Silicon Valley: State of Exception and Dispossession in Web 2.0. First Monday 15 (7). Accessed December 2, 2011. http://firstmonday.org/htbin/cgiwrap/bin/ojs/index.php/fm/article/view/2799

Jenkins, Henry. 2006. Convergence Culture. Where Old and New Media Collide. New York: New York University Press.

Lasch, Christopher. 1979. The Culture of Narcissism. Thessaloniki: Nissides. (In Greek).

Lazzarato, Maurizio. 1997. Immaterial Labor. Generation Online. Accessed October, 25, 2011. http://www.generationonline.org/c/cimmateriallabour.htm

Lemke, Thomas. 2001. "The Birth of Bio-Politics": Michel Foucault's Lecture at the College de France on Neo-Liberal Governmentality. Economy and Society 30 (2): 190-207.

Lovink, Geert, and Ned Rossiter. 2007. MyCreativity Reader: A Critique of Creative Industries. Amsterdam: Institute of Network Cultures. 
Lovink, Geert, and Ned Rossiter. 2007. Proposals for Creative Research: Introduction to the MyCreativity Reader. In MyCreativity Reader: A Critique of Creative Industries, edited by Geert Lovink and Ned Rossiter, 9-16. Amsterdam: Institute of Network Cultures.

Lovink, Geert, and Christopher Spehr. 2007. Out-Cooperating the Empire? In MyCreativity Reader: A Critique of Creative Industries, edited by Geert Lovink and Ned Rossiter, 81-96. Amsterdam: Institute of Network Cultures.

Marx, Karl. 1993/1953. Grundrisse: Foundations of the Critique of Political Economy. London: Penguin.

Mouffe, Chantal. 2004. The Democratic Paradox. Athens: Polis (in Greek).

Mumford, Lewis. 2011/1964. Utopia, the Demons of the Spirit, and the Human Potential. Thessaloniki: Nisides (in Greek). Ong, Aihwa. 2006. Neoliberalism as Exception: Mutations in Citizenship and Sovereignty. London: Duke University Press. Pasquinelli, Matteo. 2008. Animal Spirits, a Bestiary of the Common. Amsterdam: Institute of Network Cultures.

Price, Stuart. 2011. Worst Case Scenario? Governance, Mediation and the Security Regime. London: Zed Books.

Rose, Nicholas. 1999. Powers of Freedom: Reframing Political Thought. Camebridge: Cambridge University Press.

Ross, Andrew. 2007. Nice Work If You Can Get It: The Mercurial Career of Creative Industries Policy. In MyCreativity Reader: A Critique of Creative Industries, edited by Geert Lovink and Ned Rossiter, 17-40. Amsterdam: Institute of Network Cultures

Sennett, Richard. 1974. The Fall of the Public Man. London: Penguin.

Sennet, Richard. 2008. Craftsman. London: Yale University Press.

Stavrakakis, Yiannis. 2007. The Lacanian Left: Pyschoanalysis, Theory, Politics. Edinburgh: Edinburgh University Press.

Terranova Tiziana. 2000. Free Labor: Producing for the Digital Economy. Social Text 18 (2): 33-58.

Virno, Paolo. 2004. A Grammar of the Multitude: For an Analysis of Contemporary Forms of Life. Los Angeles: Semiotext(e).

Von Osten, Marion. 2007. Unpredictable Outcomes: A Reflection After Some Years of Debates on Creativity and Creative Industries. In MyCreativity Reader: A Critique of Creative Industries, edited by Geert Lovink and Ned Rossiter, 49-58. Amsterdam: Institute of Network Cultures.

Wayne, Michael. 2003. Marxism and Media Studies. Key Concepts and Contemporary Trends. London: Pluto Press.

\section{About the Author}

Yiannis Mylonas

is a Post Doctoral Researcher at the Media and Communications' Department, Lund University. He has a background in Philosophy, Social Psychology and Media Studies. His research interests depart from the theoretical foundations of Critical Theory and Post Structuralism and relate to the study of media and politics. He has published studies on discourse analysis of war representations, political subjectivity, and on the political economy of copyrights. 